\title{
Flotation techniques (FLOTAC and mini-FLOTAC) for detecting gastrointestinal parasites in howler monkeys
}

\author{
Mayra Alejandra Alvarado-Villalobos ${ }^{1}$, Giuseppe Cringoli ${ }^{2}$, Maria Paola Maurelli ${ }^{2}$, Aurelie Cambou ${ }^{3}$, Laura Rinaldi ${ }^{2}$, \\ Arturo Barbachano-Guerrero ${ }^{4}$, Roger Guevara ${ }^{5}$, Colin A. Chapman ${ }^{6}$ and Juan Carlos Serio-Silva ${ }^{* *}$
}

\begin{abstract}
Background: Analyses of environmental correlates of the composition of gastrointestinal parasite communities in black howler monkeys (Alouatta pigra) have been hindered by inadequate calibration techniques of detection and quantification methods of the parasites. Here we calibrate samples and compare the likelihood of parasite detection using two flotation techniques, FLOTAC and Mini-FLOTAC, and compare flotation solution, preservation method and dilution ratio for egg detection and counts of the most common parasites (Controrchis spp. and Trypanoxyuris spp.) in howler monkeys.

Results: For samples preserved in 5\% formalin, the Mini-FLOTAC technique was the best option for qualitative and quantitative copro-microscopic analysis. This technique displays an $83.3 \%$ and $100 \%$ detection of Controrchis spp. and Trypanoxyuris spp. infections, respectively. For the trematode Controrchis spp., more eggs per gram of feces $(E P G)$ were recorded with the flotation solution (FS) \#7 (zinc sulfate; specific gravity SG $=1.35$ ) at 1:20 and 1:25 dilution than other methods. By contrast, for the nematode Trypanoxyuris spp., the best results were recorded with FS1 (sucrose and formaldehyde; $S G=1.20$ ) at 1:10 dilution.

Conclusions: We recommend the Mini-FLOTAC technique for general use with parasite analysis on frugivore/ folivores like the howler monkey, especially if many samples are analyzed. The technique has a high detection rate and the best EPG counts, allowing the qualitative and quantitative analysis of parasite load among the species or populations without the need for specialized equipment.
\end{abstract}

Keywords: Quantitative flotation, Gastrointestinal parasites, Nematodes, Trematodes, Howler monkeys, Alouatta

\section{Background}

The accurate detection of the prevalence and intensity of gastrointestinal parasite infections is key to understanding the effect of parasites on the biology, behavior, and the conservation of hosts. Gastrointestinal parasites are most often surveyed in the feces [1] of wild host populations using light microscopy [2-4], which is particularly effective where the feces of host populations can be identified and collected in the wild, as this eliminates the need to capture or handle host individuals.

\footnotetext{
* Correspondence: juan.serio@inecol.mx

${ }^{1}$ Red de Biología y Conservación de Vertebrados, Instituto de Ecología A.C, Xalapa, 91070 Veracruz, Mexico

Full list of author information is available at the end of the article
}

An increasing number of studies have focused on the gastrointestinal parasites of howler monkeys (Alouatta spp.), in which polyparasitism is common, including helminths, protozoans and acanthocephalans [5]. Among these parasites, trematodes (Controrchis spp.) and nematodes (Trypanoxyuris spp.) are the most common gastrointestinal parasites of howler monkeys $[5,6]$. Controrchis spp. are common in most studies $[5,7]$ and may influence the ecology of the host [8]. By contrast, Trypanoxyuris spp. appear to be indicators of ecosystem health with low prevalence in human dominated landscapes and high prevalence in more natural landscapes [9]. Most studies report low levels of Controrchis spp. and Trypanoxyuris spp. parasitism in the black howler monkey (Alouatta pigra) [7, 8], possibly due to 
unsuitable sampling or analytical methods. Consequently, standardization of the copro-microscopic techniques is essential for the diagnosis of gastrointestinal parasites.

In wild primates, including howler monkeys, parasitic infections are typically detected by identifying eggs, larvae, oocysts, or cysts in the feces of the host by flotation procedures [10-15] or sedimentation techniques $[8,10,12]$. Sodium nitrate $\left(\mathrm{NaNO}_{3}\right)$ is a common flotation solution (FS) for fecal samples from wild primates [16, 17]. However, studies of black howler monkeys (Alouatta pigra) have also used sodium chloride $(\mathrm{NaCl})[11,18]$, zinc sulfate $\left(\mathrm{ZnSO}_{4}\right)$ [13-15], and sucrose $\left(\mathrm{C}_{12} \mathrm{H}_{22} \mathrm{O}_{11}\right)$ for samples preserved in $10 \%$ formalin $[8,12,14,15]$. In folivore-frugivore primates, such as Alouatta pigra [19-21], identification of parasites in fecal samples is often complicated by the high fiber content of their diet [19], as well as the common presence of pollen, plant tissue, flowers, and invertebrate fragments (accidentally ingested with the plants) $[19,21,22]$, all of which can be misclassified as parasitic structures.

We suggest that the development and calibration of parasite copro-microscopic techniques and the standardization of existing methods have not received sufficient attention, particularly as calibration is the foundation of a good diagnosis. The accuracy of fecal egg count (FEC) techniques depends on the analytic sensitivity of the technique, the choice of the flotation solution, and dilution as well as fecal preservation method $[1,4,23]$.

The aim of this study is to evaluate the efficiency of detection and counts of the eggs of the most common parasites (Controrchis spp. and Trypanoxyuris spp.) of howler monkeys, using two novel techniques, FLOTAC and Mini-FLOTAC, six flotation solutions, three different dilutions, and two preservation methods. FLOTAC and Mini-FLOTAC are innovative multivalent quantitative diagnostic techniques sufficiently accurate to estimate the number of parasites in fecal samples [1,23-25] of $1 \mathrm{~g}$ (volume = $10 \mathrm{ml}$; analytical sensitivity=1 egg, larvae, oocyst, cyst per gram of feces, EPG/LPG/OPG/ $\mathrm{CPG}$ ) with FLOTAC $[1,23]$ and up to $0.2 \mathrm{~g}$ (volume = $2 \mathrm{ml}$; analytical sensitivity $=5 \mathrm{EPG} / \mathrm{LPG} / \mathrm{OPG} / \mathrm{CPG}$ ) with Mini-FLOTAC.

\section{Methods}

\section{Sampling methods}

An additional file shows the "Guide to the recommended quali-quantitative flotation method" which describes the procedure for performing the recommended Mini-FLOTAC basic and dual technique (Additional file 1). A composite from 13 individual fecal samples of wild A. pigra individuals (360 g) was performed and divided into sub-samples depending on calibration schemes (Additional file 2: Table S1). Individuals were naturally infected with the trematode Controrchis spp. (Fig. 1a) and nematode Trypanoxyuris spp. (Fig. 1b). Two fecal preservation methods were used: (i) anaerobic storage by vacuum packing samples (VPF) in the fridge at $4{ }^{\circ} \mathrm{C}$; and (ii) a $5 \%$ formalin solution. The VPF samples were analyzed 10 days after collection.

As is typical for howler monkeys, the fecal samples had a high fiber content that made the identification of parasite difficult. Therefore, three different dilution ratios: 1:10, 1:20 and 1:25 (g of feces/ml of water or water plus fixative depending on the calibration scheme) were used to calibrate the samples. The following six FSs were used [1]: FS1 (sucrose and formaldehyde, SG =1.2); FS2 (sodium chloride, SG =1.2); FS3 (zinc sulphate, SG= 1.2); FS4 (sodium nitrate, $\mathrm{SG}=1.2$ ); FS6 (magnesium sulphate, $\mathrm{SG}=1.28$ ); and FS7 (zinc sulphate, $\mathrm{SG}=1.35$ ). The FS5 established in the protocol of Cringoli et al. [1] was not implemented because the reagent is corrosive and expensive for routine use. All FSs were prepared at room temperature, and their SG was checked with a hydrometer. For each FS, 6 replicates were performed.

\section{Calibration}

The single composite fecal sample was completely homogenized, divided into two sub-samples of $180 \mathrm{~g}$ each for analysis by the FLOTAC and Mini-FLOTAC methods. The sub-samples were further subdivided into two samples of $90 \mathrm{~g}$ each, which were either preserved in VPF or 5\% formalin at dilution ratio 1:4 (one part of feces and three of fixative). After storage, each $90 \mathrm{~g}$ sample was equally divided into three $30 \mathrm{~g}$ samples that were diluted at the following ratios 1:10, 1:20, 1:25 (g of feces/ $\mathrm{ml}$ of water or water plus 5\% formalin). Each dilution was sieved (pore size $=250 \mu \mathrm{m}$ ), the waste was discarded and the remaining sample was thoroughly homogenized.

For the FLOTAC method, 108 aliquots (in tubes) preserved by VPF and 108 aliquots preserved in 5\% formalin (36 aliquots per dilution) were used. Each aliquot contained $6 \mathrm{ml}$ of fecal suspension. A total of 216 aliquots were centrifuged for three minutes at $1500 \times \mathrm{rpm}$ (170 RCF), and the supernatant discarded, leaving only a pellet in the tube. Each pellet was randomly assigned to one of the six FSs and re-suspended in $6 \mathrm{ml}$ of each solution in a tube. With a pipette, $5 \mathrm{ml}(0.5 \mathrm{~g})$ of the resulting fecal suspension were transferred to each centrifuge chamber ( $n=216$ chambers) for analysis by the FLOTAC method, and the samples were centrifuged at $1000 \times$ rpm (120 RCF) for five minutes. Flotation in a centrifuge causes the debris to sink to the bottom of the chambers and the parasite elements to float to the top under the two ruled grids $[1,23]$. After being centrifuged, each $5 \mathrm{ml}$ sample suspension in a chamber was examined with a light microscope at $100 \times$ and $400 \times$ magnification $[1,23]$. 


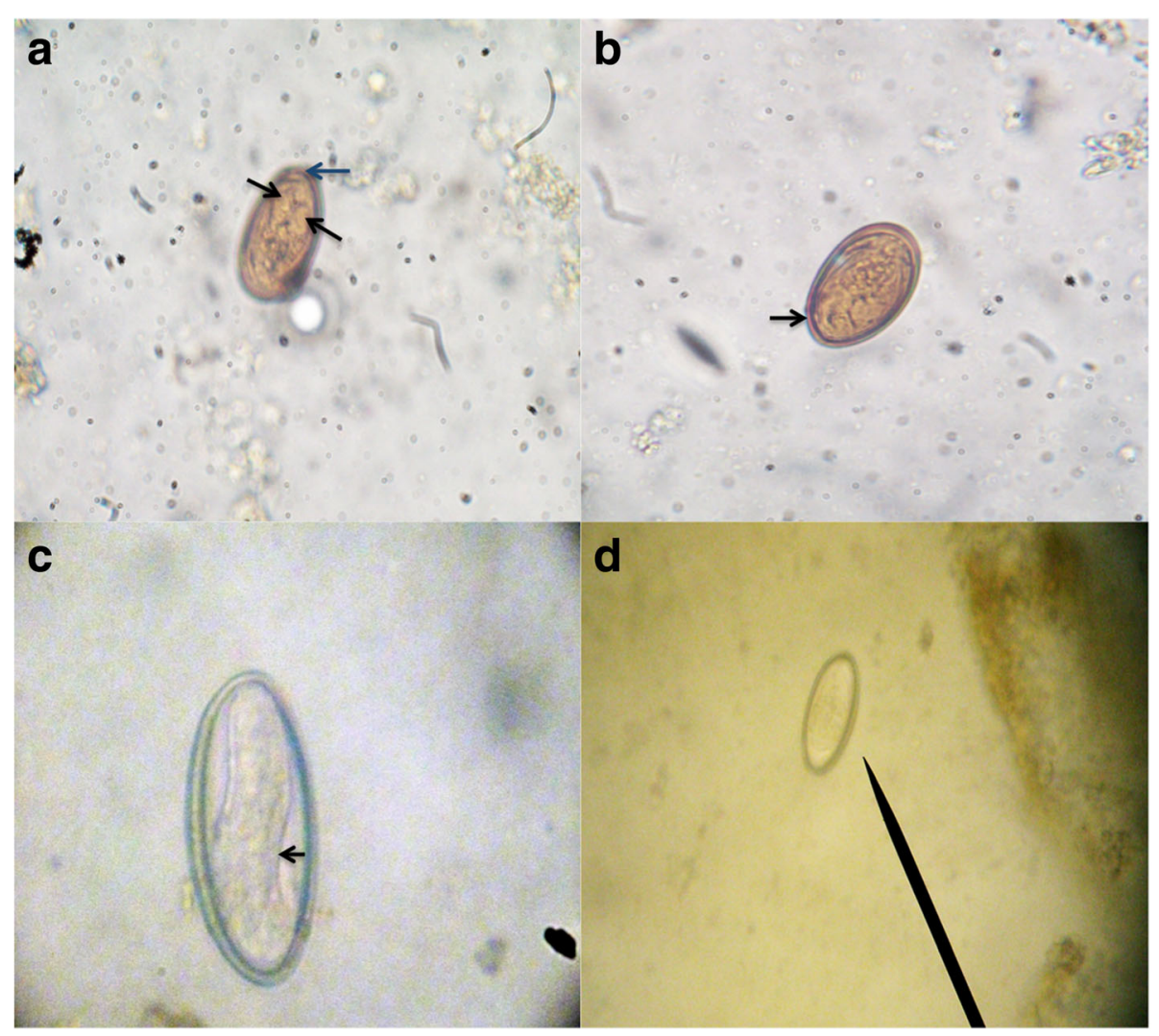

Fig. 1 Eggs of Controrchis and Trypanoxyuris. a Controrchis spp. egg (400x) measuring $35 \times 22 \mu \mathrm{m}$. The black arrows indicate the position of the miracidium, the blue arrow shows the operculum. b Controrchis spp. egg (400x) measuring $35 \times 22 \mu \mathrm{m}$. The black arrow indicates the thick wall. c Trypanoxyuris spp. egg $(1000 \times)$ measuring $36 \times 22 \mu \mathrm{m}$. The black arrow indicates the larva inside. d Trypanoxyuris spp. egg (100x) measuring $36 \times 22 \mu \mathrm{m}$

For the Mini-FLOTAC method 216 tubes were analyzed (180 g). Samples preserved by VPF $(90$ g) did not need to be centrifuged and $5 \mathrm{~g}$ of feces sample were weighed for every six replicates and homogenized them in their respective FS and dilution. For samples preserved in 5\% formalin, 108 tubes $(90 \mathrm{~g})$ were centrifuged at $1500 \times \mathrm{rpm}$ for three minutes. The supernatant was discarded, and each tube was filled with $6 \mathrm{ml}$ of the respective FS and dilution. The Mini-FLOTAC chambers were filled with $1 \mathrm{ml}(0.1 \mathrm{~g})$ of the homogenized suspension. Finally, the 216 replicates ( $n=216$ chambers) were examined for parasites using a light microscope 100x and $400 \times$ magnifications.

A total of 432 tubes $(2$ flotation methods $\times 2$ preservation methods $\times 3$ dilutions $\times 6 \mathrm{FSs} \times 6$ replicates per solution) were examined.

\section{Statistical analysis}

Infections are often described as the number of parasitic elements per gram of feces: eggs (EPG), larvae (LPG), oocysts (OPG), or cysts (CPG) per gram of feces. To obtain these values, the analytic sensitivity of the technique must be known. The analytic sensitivity is the ability to detect the smallest number of parasitic elements assessed by a technique, small values mean that the technique has a high analytic sensitivity and is capable of detecting parasitic infections even though the excreted parasites eggs are low. This value is used as a multiplication factor used to express the results in gram of feces. Both techniques used in this paper present a high analytical sensitivity compared to the most used parasitological techniques $[1,25]$.

For our work using FLOTAC, the multiplication factor is 2 when the dilution ratio is $1: 10,4$ using a $1: 20$ dilution ratio and 5 for 1:25 dilution ratio to obtain our results in EPG. For the Mini-FLOTAC technique the multiplication factors are 10 using 1:10, 20 with 1:20 dilution, and 25 when a 1:25 dilution ratio was used.

The efficiency of the methods was estimated from six replicates ( $n=6$ chambers) as the number of EPG in the flotation solution. The mean EPG, standard deviation (SD) and the coefficient of variation expressed as a percentage $[\mathrm{CV}(\%)=($ standard deviation $/$ mean of EPG $) \times$ 100] were estimated for each combination of flotation 
method, fecal preservation method, dilution and FS (Additional file 3: Table S2, Additional file 4: Table S3).

A generalized linear logistic model (binomial error distribution) was used to compare the likelihood of parasite detection (prevalence) among the combinations of flotation methods, fecal preservation methods, dilutions and FSs. Differences in the number of EPG as intensity value (or the capacity of the methods to float parasite elements) were analyzed with generalized linear models using a Poisson distribution and adjusting interactions at fourth level [glm (EPG (method + fecal preservation method + dilution + FS $) \wedge 4$, Poisson)]. Models were checked for homoscedasticity and normality of the residuals. The presence/absence of the parasite and the number of EPG counted (quantitative technique) were the respective response variables. The flotation methods, fecal preservation methods, dilutions, and FSs were explanatory variables. Initially fitted the saturated model and then followed a model simplification procedure to eliminate the explanatory variables that did not improve the model fit to the data. To find the best model we used the Akaike's information criterion (AIC) [26]. Also, when necessary, levels were conflated within a given factor to construct the simplest model. GLMs with the R package gmodels [27] were performed within the statistical program R version 3.2.0 (R Development Core Team, 2015) [28].

\section{Results \\ Controrchis spp.}

Eggs of Controrchis spp. floated only using FS2, FS3, FS6 and FS7. The values of FS2, FS3 and FS6 were grouped into a single category, due to the low numbers of eggs detected in these solutions. Only in the FS7, eggs floated with both techniques at all dilution ratios. The likelihood of detection based on presence/absence vary significantly in relation to apparatus $\left(\chi^{2}=5.5, d f=1, P=0.019\right)$, preservation methods $\left(\chi^{2}=7.4, d f=1, P=0.007\right)$ and FSs $\left(\chi^{2}=4.3, d f=1, P=0.037\right)$. The samples preserved in $5 \%$ formalin and analyzed with FLOTAC with FS7 showed the best results with a probability of detection of $83.3 \%(n=15 / 18)$ for Controrchis spp. infections.

The evaluation based on counts of EPG in flotation differ in FSs $\left(\chi^{2}=445.4, d f=1, P<0.001\right)$, preservation methods $\left(\chi^{2}=167.2, d f=1, P<0.001\right)$ and dilution ratios $\left(x^{2}=85.2, d f=2, P<0.001\right)$. All significant GLM results are shown in Additional file 5: Table S4. FS7 exhibited significantly larger counts than those obtained from the groups FS1-FS6 (Fig. 2). The highest values of EPG were
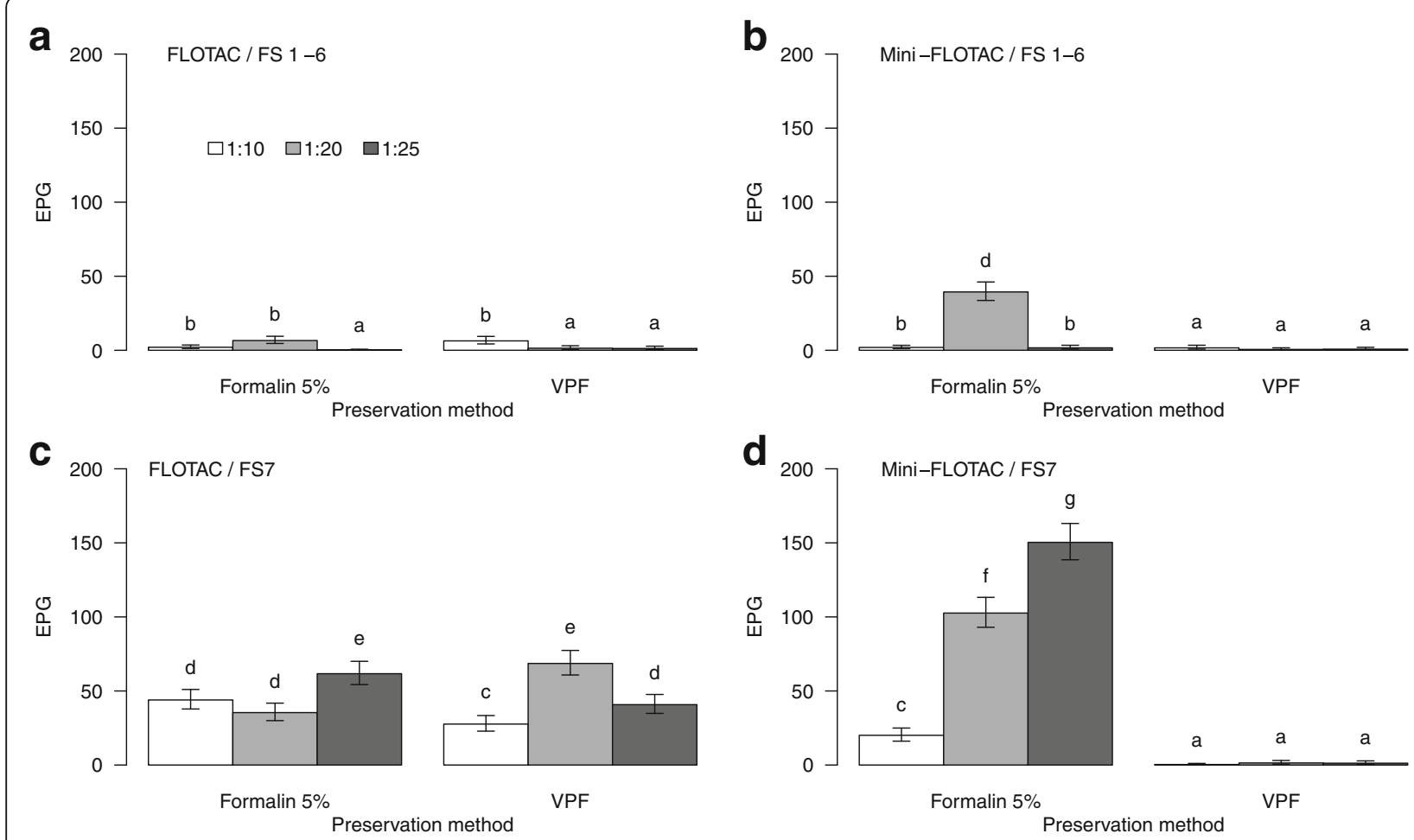

Fig. 2 Controrchis spp. total egg counts. Comparison between calibration variables: methods, FSs, preservation methods and dilutions. a Total number of EPG using the FLOTAC technique with groups FS1-FS6. b Total number of EPG using the Mini-FLOTAC technique with groups FS1-FS6. c Total number of EPG using the FLOTAC technique with FS7. $\mathbf{d}$ Total number of EPG using the Mini-FLOTAC technique with FS7. Letters above the bars indicate the homogeneous groups based on the contrasts done. Differences for bars with the same letter were not statistically significant while those with different letters were statistically different. In all the bars the standard error is represented as a measure of dispersion around the mean 
obtained by $1: 20$ and 1:25 dilution, and $5 \%$ formalin also proved their efficiency in counts of EPG in flotation. The values of EPG in flotation was better using 5\% formalin compared with VPF $(n=454$ EPG, mean $=2.1$ and $n=140 \mathrm{EPG}$, mean $=0.65$, respectively).

Although there were no differences in relation to apparatus $\left(\chi^{2}=1.1, d f=1, P=0.296\right)$, Mini-FLOTAC was marginally better than FLOTAC based on counts of EPG in flotation (Fig. 2). The most appropriate combination of elements was (i) fecal samples preserved in 5\% formalin and analyzed with FS7 at 1:20; and (ii) fecal samples preserved in 5\% formalin and analyzed with FS7 at 1:25 dilution ratio. Using Mini-FLOTAC with the both previous combination an $83.3 \%$ of detection value is obtained for Controrchis spp. infections.

\section{Trypanoxyuris spp.}

The eggs of Trypanoxyuris spp. floated with all the six FSs (Fig. 3) and there were differences in apparatus in detectability $\left(\chi^{2}=17.6, d f=1, P<0.001\right)$. The FLOTAC method was, however, better than the Mini-FLOTAC method (50.4 and 13.8\%, respectively) (Table 1).

Detection based on counts of EPG in flotation varied significantly among FSs $\left(\chi^{2}=286.8, d f=5\right.$, $P<0.001)$, preservation methods $\left(\chi^{2}=123.8, d f=1\right.$, $P<0.001)$, and dilution $\left(\chi^{2}=33.7, d f=2, P<0.001\right)$. FS1 performed best with a significantly larger EPG count than FS2 $(z=3.1, P=0.002)$, FS3 $(z=3.1, P=0.002)$ and FS4 $(z=2.0, P=0.044)$. Fecal samples preserved in 5\% formalin detected more Trypanoxyuris spp. infections with a better EPG count in flotation than VPF. All significant GLM results are shown in (Additional file 6: Table S5).

Although there were no differences related to apparatus $\left(\chi^{2}=2.0, d f=1, P=0.159\right)$ based on counts of EPG in flotation, the combination Mini-FLOTAC method using FS1 at 1:10 dilution (80 EPG, mean $=13.3 \mathrm{EPG}$, $\mathrm{SD}=5.2 \mathrm{EPG}, \mathrm{CV}=38.7 \%)$ with samples preserved in $5 \%$ formalin performed the best EPG counts. This combination detected $100 \%$ of Trypanoxyuris spp. infections

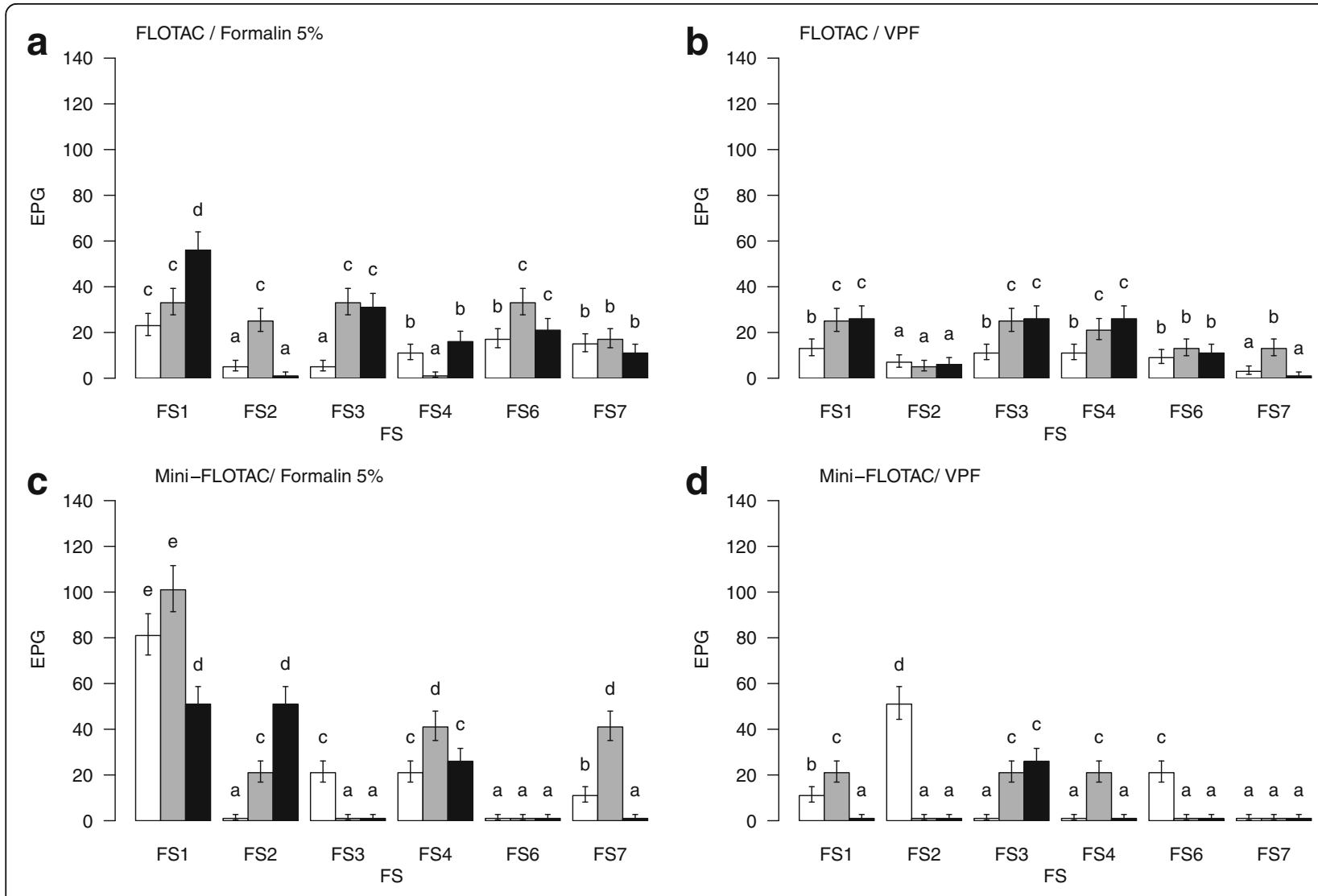

Fig. 3 Trypanoxyuris spp. total egg counts. Comparison between calibration variables: methods, FSs, preservation methods and dilutions. a Total number of EPG using the FLOTAC technique with the six FS and 5\% formalin as the preservation method. $\mathbf{b}$ Total number of EPG using the FLOTAC technique with the six FS and VPF as the preservation method. c Total number of EPG using the Mini-FLOTAC technique with the six FS and $5 \%$ formalin as the preservation method. $\mathbf{d}$ Total number of EPG using the Mini-FLOTAC technique with the six FS and VPF as the preservation method. Letters above the bars indicate the homogeneous groups based on the contrasts done. Differences for bars with the same letter were not statistically significant while those with different letters were statistically different. In all the bars the standard error is represented as a measure of dispersion around the mean 
Table 1 Generalized linear model output for Trypanoxyuris spp. detection (presence/absence)

\begin{tabular}{llll}
\hline & $d f$ & $x^{2}$ & $P$-value \\
\hline FS & 5 & 5.2 & 0.396 \\
Apparatus & 1 & 17.6 & $<0.0001^{*}$ \\
Dilution & 2 & 4.1 & 0.131 \\
\hline
\end{tabular}

*Significance at $a=0.05$. Table reflects the final output of simplification of full model

with less variation among samples compared to the same elements at 1:20 dilution (100 EPG, mean =16.6 EPG, $\mathrm{SD}=19.6 \mathrm{EPG}, \mathrm{CV}=118.0 \%)$.

\section{Discussion}

Although significant advances have been made in the parasitology and epidemiology of Alouatta pigra in the wild [5, 7-16], evaluation of the best methods to use were not available until now. We demonstrated that the likelihood of detecting a parasite and the egg count are dependent on the choice of preservation method, flotation technique, dilution ratio, and FS. In our study, many of the combinations of these elements were not adequate to detect the parasites and in a few specific combinations, the EPG counts were as much as 100 times higher, especially for Controrchis spp. These findings emphasize the need for standardization and calibration of the copro-microscopic techniques for an accurate detection and counting of parasites.

We do not know the real value of EPG of Controrchis spp. and Trypanoxyuris spp. infections although our study still provides useful guidelines. Infection levels reported in other studies of howler monkeys are generally low, the mean EPG of Controrchis spp. values reported using the sugar-flotation technique ( $S G=1.2$ ) by Kowalzik et al. [8] was $2.3 \pm 1.9$ (mean \pm SD) and by Behie et al. [7] was 3.2 \pm 1.4 eggs per gram of feces. Similarly, Behie et al. [7] reported an EPG value of $2.0 \pm$ 1.4 for Trypanoxyuris spp. using sucrose solution ( $\mathrm{SG}=$ 1.26). The general infection levels found in the present study using the best combination of elements for each parasite were 16.6 \pm 8.1 EPG (with Mini-FLOTAC, FS7 at 1:20 dilution), and $25 \pm 15.8$ EPG (with Mini-FLOTAC, FS7 at 1:25 dilution) for Controrchis spp. and 13.3 \pm 5.2 EPG for Trypanoxyuris spp. (with Mini-FLOTAC, FS1 at 1:10 dilution). For all combinations, fecal samples preserved in 5\% formalin show significantly better results.

Here FLOTAC obtained the best results for detecting the presence of Controrchis spp. and Trypanoxyuris spp. infections. FLOTAC is a cylindrical device with two $5 \mathrm{ml}$ flotation chambers, which allows up to $1 \mathrm{~g}$ of stool to be prepared for microscopic analysis [1]. However, species of the genus Alouatta are folivore-frugivore primates [19-21], and their feces have a high fiber content [19], with pollen, plant tissue, flowers, and other elements being abundant $[19,21,22]$ and all this debris accumulates in the large chambers $(5 \mathrm{ml})$ of FLOTAC hindering the quantitative analysis. As a result, we suggest the quantitative analysis of EPG using a Mini-FLOTAC as a better option. Mini-FLOTAC is considered in other studies, as the most sensitive method for detecting helminth infections compared with the formol-ether concentration and direct fecal smear methods for the diagnosis in humans $[24,29,30]$. It is also more sensitive than the McMaster (FEC technique) for the diagnosis of Eimeria in goats [31]. Barda et al. [24] reported a detection of $90 \%$ in helminth infections and $68 \%$ of protozoan infections. Also in the veterinary field Maurelli et al. [32], report a $100 \%$ of detection of the three most common intestinal nematodes in dogs (Toxocara canis, Trichuris vulpis and hookworm) with this method. In our study, with the appropriate combination of elements, Mini-FLOTAC performed good detection based on presence and EPG counts of both Controrchis spp. and Trypanoxyuris spp. avoiding the large amount of debris in the $5 \mathrm{ml}$ of FLOTAC chambers.

Mini-FLOTAC is a simple technique (FEC technique) with two $1 \mathrm{ml}$ flotation chambers, which are designed for the optimal examination of faecal sample suspensions (total volume $=2 \mathrm{ml}$ ) [24]. In our study, the probability of detection is higher $(83.3 \%$ for detection of Controrchis spp. and 100\% of Trypanoxyuris spp. infections) than in previous studies [24, 32].

The use of $5 \%$ formalin is recommended as this was associated with significantly higher egg detection and EPG counts for Controrchis spp. and Trypanoxyuris spp. infections compared with VPF. These findings are encouraging because in field conditions, high temperatures and humidity do not allow the preservation of fresh samples for later analysis and is effective to avoid degradation and loss of parasitic forms [33].

We suggest the use of zinc sulfate $(S G=1.35)$ for the detection of trematode eggs is the best option. For the detection of trematodes such as Controrchis spp., some authors use sedimentation techniques [12, 34], however, our results and those of previous studies [24, 35] showed that the flotation of this group of parasites can be achieved with FSs that have a high specific gravity. Also, Barda et al. [25] found that the FS7 is the most sensitive solution to detect Ascaris lumbricoides infections using the Mini-FLOTAC method, which is of interest because species of this parasite genus has also been found in howler monkeys [10, 36].

For nematodes such as Trypanoxyuris spp., FS1 (sucrose and formaldehyde; $\mathrm{SG}=1.20$ ) is recommended. These FSs have been used before on howler monkey fecal samples with different specific gravity $[12,13]$. It is relevant to mention that, in this study, a popular 
solution used for copro-microscopic analysis of Alouatta pigra, FS2 [11, 18], provided a low detection of the parasites; Trypanoxyuris spp. were detected in $18.1 \%(n=13$ / 72) of samples and Controrchis spp. in $2.8 \%(n=2 / 72)$ of infections. Similarly, our results showed that FS4, which is considered optimal for samples from wild primates $[16,17]$, was not suitable for the analysis of feces of howler monkeys, because it did not detect the presence of trematodes, and Trypanoxyuris spp. were detected only in $29.2 \%(n=21 / 72)$ of samples.

If a qualitative or quantitative analysis of parasites of Alouattais needed, we suggest Mini-FLOTAC with the different combination of elements shown (depending on the parasite group to be detected) is an appropriate method (Additional file 1). Our recommendations are made based on two species of parasites belonging to two parasitic groups (trematodes and nematodes), but the richness of parasites reported in Alouatta spp. is higher, thus similar studies evaluating different species are needed [24]. Finally, it was not possible to calibrate with fresh samples because FLOTAC technique needed specialized equipment (large volume or microtiter centrifuge) [23] that was not possible to use in the field. However, it is also important to compare different preservation methods against fresh samples [24, 37].

\section{Conclusions}

This is the first in-depth calibration of fecal egg count flotation methods for analyzing samples from wild howler monkeys and should be applicable for comparisons of populations and species of howlers and other similar frugivore/folivores. The Mini-FLOTAC method is a promising technique for the qualificative and quantitative analysis of nematodes and trematodes in howler monkeys, and can be used in field without specialized equipment. For the trematode Controrchis spp. the highest EPG values were recorded with FS7 at 1:20 and 1:25 dilution; for the nematode Trypanoxyuris spp. the highest EPG values were recorded with FS1 at 1:10 dilution, for samples preserved in $5 \%$ formalin. These combinations achieved an $83.3 \%$ detection of Controrchis spp. and 100\% of Trypanoxyuris spp. infections.

\section{Additional files}

Additional file 1: Guide to the recommended quali-quantitative flotation method. (DOCX $14 \mathrm{~kb}$ )

Additional file 2: Table S1. Table showing in-depth calibration scheme. (DOCX $19 \mathrm{~kb}$ )

Additional file 3: Table S2. Controrchis spp. egg counts, stratified by flotation and preservation method, dilution and flotation solutions. (DOCX $19 \mathrm{~kb})$
Additional file 4: Table S3. Trypanoxyuris spp. egg counts, stratified by flotation and preservation method, dilution and flotation solutions. (DOCX $25 \mathrm{~kb}$ )

Additional file 5: Table S4. Generalized linear model output for Controrchis spp. egg counts. (DOCX $16 \mathrm{~kb}$ )

Additional file 6: Table S5. Generalized linear model output for Trypanoxyuris spp. egg counts. (DOCX $16 \mathrm{~kb}$ )

\section{Abbreviations}

CV: Coefficient of variation; EPG: Eggs per gram of feces; EPG/LPG/OPG/ CPG: Eggs/larvae/oocysts/cyst per gram of feces; FEC: Fecal egg count; FS1: Sucrose and formaldehyde/specific gravity SG $=1.2 ;$ FS2: Sodium chloride, SG = 1.2; FS3: Zinc sulfate, SG = 1.2; FS4: Sodium nitrate, SG = 1.2; FS6: Magnesium sulfate, SG = 1.28; FS7: Zinc sulfate, SG = 1.35; G: Gram; GLMs: Generalized linear models; SD: Standard deviation; VPF: Vacuum packing in a fridge $\left(4^{\circ} \mathrm{C}\right)$

\section{Acknowledgements}

We thank the Tejero family for their assistance during fieldwork, especially the field assistant (Lolo, deceased). We thank landowners (Doña Chona, deceased, Doña Tila and Don Polo) for allowing us to work on their private properties. We thank my committee members Dr Luis Manuel Garcia Feria and Dr Martha Bonilla Moheno (INECOL). We thank Julio García Hernández for their collaboration providing the photographs of the eggs of the parasites. Finally, we appreciate the invaluable help of the Medicine Conservation Laboratory of the Instituto Politécnico Nacional, México (Don Mario, Omar, Dr Polo, Dr Nogueda).

\section{Funding}

JCSS supported most of the costs of this work including travel and lab analysis expenses and MAAV was supported by a master degree grant (CONACYT, scholarship number 280637). INECOL provided support through an academic retreat program.

\section{Availability of data and materials}

The data used and/or analyzed during the current study are available from the corresponding author upon reasonable request.

\section{Authors' contributions}

MAAV, GC, MPM, JCSS, LR and ABG conceived and designed the study. MAAV and AC performed the experiments. MAAV identified specimens and built the database. RG performed statistical analyses. MAAV, ABG, GC, MPM, JCSS, RG and CAC wrote the manuscript; all authors provided relevant input at different stages of manuscript preparation. All authors read and approved the final manuscript.

Ethics approval and consent to participate

Sampling permit (number SEMARNAT:SGPA/DGVS/05938/08) was provided by Secretaría de Medio Ambiente y Recursos Naturales (SEMARNAT).

\section{Consent for publication}

Not applicable

\section{Competing interests}

GC is the inventor and current patent holder of the FLOTAC and MiniFLOTAC methods. The methods will be licensed free of charge to the WHO and interested public non-commercial research centers. None of the other authors declare any conflict of interest concerning the work reported in this paper.

\section{Publisher's Note}

Springer Nature remains neutral with regard to jurisdictional claims in published maps and institutional affiliations.

\section{Author details}

${ }^{1}$ Red de Biología y Conservación de Vertebrados, Instituto de Ecología A.C, Xalapa, 91070 Veracruz, Mexico. ${ }^{2}$ Unit of Parasitology and Parasitic Diseases, Department of Veterinary Medicine and Animal Productions, University of Naples Federico II, Naples, Italy. ${ }^{3}$ ENSAIA (Ecole National e Supérieure d'Ágronomie et des Industries Alimentaires), Vandoeuvre-lés-Nancy, France. 
${ }^{4}$ Laboratorio de Medicina de Conservación, Departamento de Estudios de Posgrado e Investigación, Escuela Superior de Medicina, Instituto Politécnico Nacional, México, Mexico. ${ }^{5}$ Red de Biología Evolutiva, Instituto de Ecología A.C, Xalapa, 91070 Veracruz, Mexico. ${ }^{6}$ Department of Anthropology \& McGill School of Environment, McGill University, Quebec, Montreal H3A 2T7, Canada.

Received: 16 June 2017 Accepted: 12 November 2017

Published online: 23 November 2017

\section{References}

1. Cringoli G, Rinaldi L, Maurelli MP, Utzinger J. FLOTAC: New multivalent techniques for qualitative and quantitative copromicroscopic diagnosis of parasites in animals and humans. Nat Protoc. 2010;5:503-15.

2. Cringoli G, Rinaldi L, Veneziano V, Capelli G, Scala A. The influence of flotation solution, sample dilution and the choice of McMaster slide area (volume) on the reliability of the McMaster technique in estimating the faecal egg counts of gastrointestinal strongyles and Dicrocoelium dendriticum in sheep. Vet Parasitol. 2004;123:121-31.

3. Ward MP, Lyndal-Murphy MBF. Evaluation of a composite method for counting helminth eggs in cattle faeces. Vet Parasitol. 1997;73:186-7.

4. Mes THM, Eysker M, Ploeger HWA. Simple, robust and semi-automated parasite egg isolation protocol. Nat Protoc. 2007;2:486-9.

5. Vitazkova SK. Overview of parasites infecting howler monkeys, Alouatta spp, and potential consequences of human-howler interactions. In: Huffman MA, Colin AC, editors. Primate parasite ecology: the dynamics and study of hostparasite relationships. Cambridge, UK: Cambridge University Press; 2009. p. 371-85.

6. Alvarado-Villalobos MA. Fluctuación de la comunidad de parásitos gastrointestinales de Alouatta pigra en diferentes condiciones de hábitat. MSc dissertation, Instituto de Ecologia, A.C; 2015.

7. Behie AM, Kutz S, Pavelka MS. Cascading effects of climate change: do hurricane-damaged forests increase risk of exposure to parasites? Biotropica. 2013;46:25-31

8. Kowalzik BK, Pavelka MSM, Kutz SJ, Behie A. Parasites, primates, and antplants: clues to the life cycle of Controrchis spp. in black howler monkeys (Alouatta pigra) in southern Belize. J Wildl Dis. 2010:46:1330-4.

9. Vitazkova SK. The effects of demography and ecology on the parasites of wild black howler monkeys, A.pigra, from Belize and southern México. PhD thesis, Columbia University; 2005.

10. Eckert KA, Hahn NE, Genz A, Kitchen DM, Stuart MD, Averbeck GA, et al. Coprological surveys of Alouatta pigra at two sites in Belize. Int J Primatol. 2006;27:227-38

11. Trejo-Macías G, Estrada A, Mosqueda Cabrera MÁ. Survey of helminth parasites in populations of Alouatta palliata mexicana and A. pigra in continuous and in fragmented habitat in southern Mexico. Int J Primatol. 2007;28:931-45.

12. Trejo-Macías G, Estrada A. Risk factors connected to gastrointestinal parasites in mantled Alouatta palliata mexicana and black howler monkeys Alouatta pigra living in continuous and in fragmented rainforests in Mexico. Curr Zool. 2012;58:375-84.

13. Vitazkova SK, Wade SE. Effects of ecology on the gastrointestinal parasites of Alouatta pigra. Int J Primatol. 2007;28:1327-43.

14. Vitazkova SK, Wade SE. Free-ranging black howler monkeys, Alouatta pigra, in southern Belize are not parasitized by Controrchis biliophilus. Primates. 2012:53:333-6.

15. Vitazkova SK, Wade SE. Parasites of free-ranging black howler monkeys (Alouatta pigra) from Belize and México. Am J Primatol. 2006;68:1089-97.

16. Gillespie TR. Non-invasive assessment of gastrointestinal parasite infections in free-ranging primates. Int J Primatol. 2006;27:1129-43.

17. Gillespie TR, Nunn CL, Leendertz FH. Integrative approaches to the study of primate infectious disease: implications for biodiversity conservation and global health. Am J Phys Anthropol. 2008;47(Suppl 51):53-69.

18. González-Hernández M, Rangel-Negrín A, Schoof VAM, Chapman CA, Canales-Espinosa D, Dias PAD. Transmission patterns of pinworms in two sympatric congeneric primate species. Int J Primatol. 2014;35:445-62.

19. Aristizábal-Borja J. Estrategias de forrajeo y características nutricionales de la dieta del mono aullador negro (Alouatta pigra) en un ambiente fragmentado. Xalapa, Veracruz: MSc dissertation, Instituto de Ecología, A c; 2013 .
20. Righini N, Garber PA, Rothman JM. The effects of plant nutritional chemistry on food selection of Mexican black howler monkeys (Alouatta pigra): the role of lipids. Am J Primatol. 2015;79:1-15.

21. Dias PAD, Rangel-Negrín A. Diets of howler monkeys. In: Kowalewski M, Garber P, Cortés-Ortiz L, Urbani B, Youlatos D, editors. Howler monkeys. Developments in primatology: progress and prospects. New York, NY: Springer; 2015. p. 21-56.

22. Pozo-Montuy G, Serio-Silva JC. Comportamiento alimentario de monos aulladores negros (Alouatta pigra Lawrence, Cebidae) en hábitat fragmentado en Balancán, Tabasco, México. Acta Zool Mex. 2006;22:53-66.

23. Cringoli G. FLOTAC, a novel apparatus for a multivalent faecal egg count technique. Parassitologia. 2006;48:381-4

24. Barda BD, Rinaldi L, lanniello D, Zepherine H, Salvo F, Sadutshang T, et al. MiniFLOTAC, an innovative direct diagnostic technique for intestinal parasitic infections: experience from the field. PLoS Negl Trop Dis. 2013;7:e2344.

25. Barda B, Cajal P, Villagran E, Cimino R, Juarez M, Krolewiecki A, et al. MiniFLOTAC, Kato-Katz and McMaster: three methods, one goal; highlights from north Argentina. Parasit Vectors. 2014;7:271

26. Sakamoto $Y$, Ishiguro M, Kitagawa G. Akaike information criterion statistics. Boston: D. Reidel Publishing Company; 1986

27. Gregory RW, Bolker B, Lumley T, Johnson RC. Gmodels:various R programming tools for model fitting. R package version 2.15.4.1. 2013. URL. https://sourceforge.net/projects/r-gregmisc/

28. Core Team R. R: a language and environment for statistical computing. Vienna, Austria: R Foundation for Statistical Computing; 2015. URL: http://www.R-project.org/

29. Barda B, lanniello D, Salvo F, Sadutshang T, Rinaldi L, Cringoli G, et al. "Freezing" parasites in pre-Himalayan region, Himachal Pradesh: experience with mini-FLOTAC. Acta Trop. 2013;130:32-7.

30. Barda B, Zepherine H, Rinaldi L, Cringoli G, Burioni R, Clementi M, et al. MiniFLOTAC and Kato-Katz: helminth eggs watching on the shore of Lake Victoria. Parasit Vectors. 2013;61:220

31. Silva LMR, Villa-Vicosa MJM, Maurelli MP, Morgoglione ME, Cortes HCE, Cringoli G, et al. Mini-FLOTAC for the diagnosis of Eimeria infection in goats: an alternative to McMaster. Small Rumt Res. 2013:114:280-3.

32. Maurelli MP, Rinaldi L, Alfano S, Pepe P, Coles GC, Cringoli G. Mini-FLOTAC, a new tool for copromicroscopic diagnosis of common intestinal nematodes in dogs. Parasit Vectors. 2014;6:356

33. Rinaldi L, Maurelli MP, Musella V, Santaniello A, Coles GC, Cringoli G. FLOTAC: An improved method for diagnosis of lungworm infections in sheep. Vet Parasitol. 2010;169:395-8.

34. Dryden MW, Payne PA, Ridley R, Smith V. Comparison of common fecal flotation techniques for the recovery of parasite eggs and oocysts. Vet Ther. 2005:6:15-28.

35. De Souza-Dantas LM, Pereira Machado Bastos O, Brener B, Salomão M, Guerrero J, Vollmer Labarthe N. Técnica de centrífugo-flutuaçãocom sulfato de zinco no diagnóstico de helmintos gastrintestinais de gatos domésticos. Cienc Rural. 2007:37:904-906.

36. Stuart MD, Pendergast V, Rumfelt S, Pierberg S, Greenspan L, Glander KE, et al. Parasites of wild howlers (Alouatta spp). Int J Primatol. 1998;19:493-512.

37. Cringoli G, Rinaldi L, Maurelli MP, Morgoglione ME, Musella V, Utzinger J. Ancylostoma caninum: calibration and comparison of diagnostic accuracy of flotation in tube, McMaster and FLOTAC in faecal samples of dogs. Exp Parasitol. 2011;128:32-7.

\section{Submit your next manuscript to BioMed Central and we will help you at every step:}

- We accept pre-submission inquiries

- Our selector tool helps you to find the most relevant journal

- We provide round the clock customer support

- Convenient online submission

- Thorough peer review

- Inclusion in PubMed and all major indexing services

- Maximum visibility for your research

Submit your manuscript at www.biomedcentral.com/submit 